\title{
Prolactin does not delay early tumour formation of breast cancer cells, but in combination with DNA damage can trigger an anti-tumour immune response
}

Ödül Karayazi Atici, ${ }^{1}$ and Carrie S. Shemanko ${ }^{1,2}$

${ }^{1}$ Department of Biological Sciences, ${ }^{2}$ Arnie Charbonneau Cancer Institute, University of Calgary, Calgary, Alberta T2N 1N4, Canada

\section{Running title}

PRL and the DDR trigger an anti-tumour immune response

\section{Keywords}

Prolactin, DNA damage response, natural killer cells, breast cancer, xenograft

\section{Financial support}

This research was made possible by grants made to CSS from the Alberta Cancer Foundation (\#27246), the Canadian Cancer Society (\#300072) and the University of Calgary.

\section{Corresponding Author}

Carrie S. Shemanko, Arnie Charbonneau Cancer Institute, Department of Biological Sciences, University of Calgary, 2500 University Dr. NW, Calgary, AB, T2N 1N4 shemanko@ucalgary.ca, 


\section{ABSTRACT}

There are conflicting reports of the role of prolactin in breast cancer, and its role within the context of the tumour microenvironment is not well understood. In our previous study, we demonstrated a cross-talk between the ataxia telangiectasia-mutated (ATM) DNA damage response pathway and the PRL-Janus-kinase-2 (JAK2)-signal transducer and activator of transcription-5 (STAT5)-heat shock protein-90 (HSP90) pathway. In order to investigate the role of PRL in tumour initiation and the effect of DNA damage in vivo, we used a model of breast cancer initiation that assesses the ability of breast cancer cells to initiate orthotopic xenograft tumour formation after DNA damage. Breast cancer cells engineered to secrete human PRL or the control cells, were treated with the DNA damaging agent doxorubicin or vehicle and injected into mammary fat pad of immune deficient SCID mice. PRL secretion from human breast cancer cells did not change the tumour latency compared to controls, although combined doxorubicin and PRL treatment increased tumour latency. Injection of a natural killer (NK) cell-depleting antibody, anti-asialo GM1, resulted in faster tumour formation only in the PRL-secreting breast cancer cells that were pre-treated with doxorubicin, and not PRL-only or empty vector controls. These results may shed light on the conflicting reports of PRL in breast cancer, and demonstrate that at least within the context of breast cancer cell DNA damage, that PRL exposure in the tumour microenvironment does not delay tumour initiation, but PRL together with DNA damage of breast cancer cells results in reduced tumour volume over time due to asialo-GM1positive immune cells. 


\section{Introduction}

Prolactin (PRL) is a peptide hormone that promotes proliferation, differentiation, survival and motility of mammary epithelial and mammary or breast tumour cells by inducing several signalling pathways upon binding to the PRL receptor (PRLR) (Shemanko, 2016). Although confirmed as a lactogenic hormone (Horseman, 1997), its interaction with the PRLR is also implicated in the progression and metastasis of breast cancer (Arendt and Schuler, 2008, Sutherland et al., 2016, Yonezawa et al., 2015). PRL is secreted from the pituitary gland, as well as from extrapituitary sites in humans where it behaves as a paracrine/autocrine signalling molecule (Ben-Jonathan et al., 1996, Muthuswamy, 2012). Recent studies demonstrated that autocrine PRL in NRL-PRL transgenic mice contributes to increased mammary tumor formation (Arendt et al., 2011, Rose-Hellekant et al., 2003, O'Leary et al., 2015).

PRL is a potential survival factor against apoptosis (Perks et al., 2004) and its proliferative effect is due to JAK2/MAPK activation (Yamauchi et al., 2000). PRL activated Tec/Vav/Rac pathway (Miller et al., 2005) and that of NEK3 is indicated in increased motility and invasion of breast cancer cells (Miller et al., 2007). Increased levels of autocrine PRL secretion from breast cancer cells were shown to induce proliferation of the cells, enhance PRLR expression and accelerate tumour growth (Liby et al., 2003). PRL has been demonstrated to have role in cytotoxic resistance of breast cancer to variety of chemotherapy drugs in vitro (Idelman et al., 2011, LaPensee and Ben-Jonathan, 2010).

In our previous study (Karayazi Atici et al. 2018), we demonstrated that PRL increases the viability of breast cancer cells treated with DNA-damaging agents, doxorubicin or etoposide, and identified part of the molecular mechanism. The PRL- 
induced cellular resistance to DNA-damaging agents was specific to the PRLR and the DNA-damage response protein, ATM, was required for the PRL- Janus-kinase-2 (JAK2)signal transducer and activator of transcription-5 (STAT5)-heat shock protein-90 (HSP90) pathway to mediate this resistance. This led us to test the hypothesis that PRL would increase tumour volume of DNA damaged cells in a xenograft model.

Most experimental lines indicate that PRL will promote tumour growth in xenograft models (Arendt et al., 2011, Liby et al., 2003, Wennbo et al., 1997), however, there are some observations that PRL may have the opposite effect. MDA-MB-231 triple negative breast cancer cells that were engineered to express the long form of the PRLR resulted in decreased tumor growth with PRL treatment in the non-obese diabetic (NOD)/SCID xenograft model (Lopez-Ozuna, 2019). Those studies emphasize the complexity of PRL signaling and the need to understand delineate the conditions by which PRL has differing effects in breast cancer.

In this study, we used an orthotopic model to investigate the role of autocrine/paracrine PRL in breast tumour progression in the context of DNA damage and asialo-GM1 reactive immune cells. SCID mice have severe deficiency in T and B cells, however, they have active NK cells present, which sometimes limits growth of human xenografts (Dorshkind 1985, Dewan et al., 2005). In order to deplete the activity of NK cells in mice models, an anti-asialo-GM1 antibody was developed (Kasai et al., 1981). Our experiments indicate that autocrine PRL does support the initiation and growth of xenografts, but that the combination of PRL and the DNA damage response triggers attack from asialo-GM1-positive immune cells in SCID mice. 


\section{Materials and Methods}

\section{Materials}

Doxorubicin (Sigma-Aldrich Canada Co., Oakville, ON, Canada), 10 mg, was dissolved in sterile DMSO in a final concentration of $100 \mathrm{mM}$ and stored at $-20^{\circ} \mathrm{C}$ protected from light. For westerns we used a monoclonal anti-human PRL antibody (R\&D System, Minneapolis, MN, USA), rabbit anti-STAT5 (phospho Y694) primary antibody [E208] (Abcam), mouse

STAT5 primary antibody (Transduction Laboratories, BD BioSciences, San Jose, CA, USA), rabbit anti-H3 primary antibody (Millipore, Billerica, MA, USA), anti-GRB2 (Transduction Laboratories, BD Biosciences, Clone 81), and the rabbit monoclonal Ki-67 antibody (Thermo Scientific, Ontario, Canada).

\section{Cell culture and cell lines}

Three cell lines were used in this study. PRL-responsive MCF7 (estrogen receptor+, p53 wild type) human breast cancer cells, obtained and authenticated from American Type Culture Collection, were used within 6 months when revived from frozen storage. Two additional independent lines were engineered, as described below, to enable PRL secretion, and an empty vector control, and passaged up to maximum 30 passages post expansion. Cell lines were maintained in DMEM (Invitrogen, Burlington, ON, Canada), supplemented with 10\% fetal bovine serum (PAA Laboratories Inc., Etobicoke, $\mathrm{ON}), 100 \mu \mathrm{g} / \mathrm{ml}$ streptomycin and $100 \mathrm{units} / \mathrm{ml}$ penicillin, $2 \mathrm{mM}$ L-glutamine (Invitrogen, Burlington, ON, Canada), 800 mg/ml Zeocin (Invivogen, San Diego, CA, USA), also 10 
$\mu \mathrm{g} / \mathrm{ml}$ insulin (BD Biosciences, Mississauga, ON). Mycoplasma testing was routinely performed using pan-species primers and PCR.

\section{Creation of syngeneic lines}

In order to prepare stable cell lines of MCF7 cells engineered to secrete autocrine PRL or carry the empty vector (EV), MCF7hPRL and MCF7 control (EV) cell lines, polyethyleminine (PEI) transfection was used. PEI MW25K (Polyscience Inc., Warrington, $\mathrm{Pa}$, USA) was dissolved in water to final stock concentration of $1 \mathrm{mg} / \mathrm{ml}$. The human PRL coding sequence was cloned into pcDNA3.1/Zeo(+) mammalian expression vector (plasmid a gift from Dr. Vincent Goffin, Inserm and University Paris Descartes, Paris, France) (Liby et al. 2003). The expression of hPRL was driven by the cytomegalovirus promoter. Empty pcDNA3.1/Zeo(+) plasmid was prepared as control for the human PRL plasmid. The stably transfected cells carrying the Zeocin antibiotic resistance gene (Sh-ble) were selected with and maintained in Zeocin $(800 \mathrm{mg} / \mathrm{ml})$ (Invivogen, San Diego, CA, USA). Following 10-15 days of incubation in the presence of Zeocin, the colonies were selected with cloning cylinders (Fisher Scientific, Toronto, ON, Canada) using Dow Corning high-vacuum grease (Fisher Scientific, Toronto, ON, Canada). Cells carrying the empty vector were confirmed by PCR.

RNA was extracted from breast cancer cells using a Qiagen RNEasy Mini Kit (Qiagen Inc., Mississauga, ON, Canada) according to manufacturer's protocol. Complimentary DNA (cDNA) was synthesized from 2 ug of RNA using Superscript II Reverse Transcriptase kit (Invitrogen) according to the manufacturer's protocol.

All primers were designed using the NCBI Primer Blast-program. The Operon Oligo Analysis tool was used to detect possible primer dimers and self-complementation 
was identified with IDT Oligo Analyzer. The desired primers were obtained from University of Calgary DNA Synthesis Lab (Calgary, AB). Quantitative polymerase chain reactions (qPCR) were carried out using iTaq Universal SYBR Green Supermix (Biorad, Mississauga, ON, Canada) with $1 \mathrm{ml}$ of each forward and reverse primer (final primer concentration of $200 \mathrm{mM}$ ) (Table 1). The following protocol was performed for amplification of Sh ble gene: $95^{\circ} \mathrm{C}$ for 2 minutes, 40 cycles of $95^{\circ} \mathrm{C}$ for 5 seconds, $60{ }^{\circ} \mathrm{C}$ for 30 seconds, $78{ }^{\circ} \mathrm{C}$ for 20 seconds, and final extension step of $72{ }^{\circ} \mathrm{C}$ for 10 minutes, and following protocol was used for amplification of YWHAZ gene: $95^{\circ} \mathrm{C}$ for 2 minutes, 40 cycles of $95{ }^{\circ} \mathrm{C}$ for 10 seconds, $60{ }^{\circ} \mathrm{C}$ for 30 seconds, $78{ }^{\circ} \mathrm{C}$ for 20 seconds, and final extension step of $72{ }^{\circ} \mathrm{C}$ for 10 minutes in the BioRad MJMini Opticon Real-Time PCR System.

\section{Nuclear lysate extract}

The nuclear lysate extract was used to extract p-Stat5, Stat5 and Histone-H3 proteins, as previously described (Perotti et al., 2012). In order to determine p-Stat5 levels, cells were plated and the next day treated 30 minutes with human recombinant prolactin before being scraped in cold 1 XPBS.

\section{Whole cell extract}

Cells were plated and cultured for 7 days before protein extraction. Cells were directly scraped in 1XSDS buffer and after washing with 1XPSB, followed by sonication three times for 5 seconds with 5 seconds intervals at \#5 (on dial) (Fisher Scientific 60 Sonic Dismembrator) on ice. Protein samples were snap frozen and stored at $-80{ }^{\circ} \mathrm{C}$ until use. 


\section{Immunoblotting for STAT5, p-STAT5, Histone-H3, GRB2 and PRL}

Immunoblotting for STAT5 p-STAT5, and GRB2 were as previously described (Karayazi Atici et al., 2018). In order to detect Histone-H3, the PVDF membrane was wet with methanol and blocked in $3 \%$ dried skim milk in PBS overnight at $4{ }^{\circ} \mathrm{C}$, and washed three times with TBST $0.05 \%$. The membrane was incubated with rabbit anti-H3 primary antibody (1:1000 dilution) in $3 \%$ dried skim milk in PBS overnight at $4{ }^{\circ} \mathrm{C}$, washed and incubated in HRP conjugated goat anti rabbit secondary antibody (1:10000 dilution) in 3\% dried skim milk in PBS for 1 hour before chemiluminescence detection as described (Perotti et al., 2008). In order to detect PRL, the membrane was blocked in 3\% dried skim milk in TBST $0.1 \%$ for 2 hours, washed and incubated in monoclonal anti-human PRL antibody (1:100 dilution) in 5\% dried skim milk in TSBT $0.1 \%$ overnight at $4^{\circ} \mathrm{C}$. The next day the blot was washed and incubated in HRP conjugated goat anti-mouse secondary antibody (1:10000 dilution) in 5\% dried skim milk in TBST $0.1 \%$ for 30 minutes before washing and chemiluminescence detection.

\section{Secreted protein extraction from conditioned media}

To investigate secreted PRL levels from MCF7hPRL cells, 1x $10^{6}$ cells were plated into $10 \mathrm{~cm}$ plates and cultured for 7 days. A total of $1 \mathrm{ml}$ conditioned media was removed from the cells and transferred into microcentrifuge tubes and centrifuged at $4^{\circ} \mathrm{C}$ at 13,200 rpm for 15 minutes. Centrifuged conditioned media containing secreting proteins was transferred into a new cold microcentrifuge tube, snap frozen and stored at $-80{ }^{\circ} \mathrm{C}$ until use (Howell et al., 2008). 


\section{Xenograft Animal Models}

All animal procedures were carried out under strict in accordance with the Canadian Council for Animal Care guidelines and ethics approval from the University of Calgary Life and Environmental Sciences Animal Care Committee.

Nine-week-old Fox Chase SCID female mice (strain 236) were purchased from Charles River Laboratories (Montreal, QC, Canada) and 5 female mice were used per experimental group, with three different trials of the study. In order to deliver estrogen to the mice, $17 \mathrm{~b}$-Estradiol pellets $(0.72 \mathrm{mg} /$ pellet, 60 day release, Cat. No. SE-121) were obtained from Innovative Research of America (IRA, Sarasota, Florida, USA) and inserted subcutaneously. A second pellet was inserted after 60 days in the 120 day-experiment. Three days after insertion of the first pellet, breast cancer cells were injected into the 4th mammary fat pads as described below. The contralateral mammary fat pads were injected with PBS and Trevigen Cultrex BME mixture (Cedarlane, Burlington, ON, Canada).

Four experimental groups were used as follow, MCF, MCF7+dox, MCF7hPRL, MCF7hPRL+dox. MCF7 control and MCF7hPRL cells were plated and the following day indicated groups were treated with doxorubicin $(1 \mathrm{mM})$ for 2 hours and recovered for 48 hours. Cells were washed twice with $1 \mathrm{X}$ PBS and trypsinized. Following centrifugation at $400 \mathrm{rpm}$ for 4 minutes cells were resuspended in media and counted in order to obtain $1 \mathrm{x}$ $10^{6}$ cells per mouse. The counted cells were centrifuged at $400 \mathrm{rpm}$ for 4 minutes at $4^{\circ} \mathrm{C}$ one more time and the pellets were washed with 1 XPBS followed by the last centrifugation step at $400 \mathrm{rpm}$ for 4 minutes at $4^{\circ} \mathrm{C}$. The washed pellets were resuspended in $100 \mathrm{ml}$ cold PBS and $100 \mathrm{ml}$ Cultrex BME mixture. Cells were injected into the 4th mammary fat pad of mice based on the experimental groups. In order to deplete NK cell activity in SCID 
mice, $20 \mathrm{ul}$ of the anti-mouse asialo-GM1 (Cedarlane, Burlington, ON, Canada) was injected intraperitoneally every 3-4 days for the duration of the experiment. Tumour volumes were calculated as follows: $\left[\mathrm{V}=\left(\mathrm{W}^{2} \times \mathrm{L}\right) / 2\right]$ (Faustino-Rocha et al., 2013).

\section{Immunohistochemistry for Ki-67}

Frozen tissue blocks in O.C.T Embedding compound were sectioned at $8 \mathrm{~mm}$ thickness at $-30^{\circ} \mathrm{C}$ using a cryostat. Sectioned tissues were mounted on coated slides (Fisher Scientific, Ontario, Canada) and then sections were dried at room temperature overnight. The slides were stored at $-80^{\circ} \mathrm{C}$ until staining. The slides were thawed at room temperature for 15 minutes prior to immunohistochemistry staining using Envision+ Dual Link System-HRP (DAB+) kit (DAKO, Carpinteria, CA, USA). Following fixation in 95\% ethanol, the slides were washed three times 5 minutes each in wash buffer containing 0.05M Tris- $\mathrm{HCl} \mathrm{pH} 7.6,0.15 \mathrm{M} \mathrm{NaCl}, 0.25 \%$ Tween-20. The slides were blocked in Dual Endogenous Enzyme Block (DAKO) at room temperature and then washed three times 5 minutes each in wash buffer, followed by permeabilization in $0.25 \%$ Triton-X 100 in wash buffer and washing three times 5 minutes each in wash buffer. To prevent nonspecific binding, sections were blocked in 5\% BSA in wash buffer for 10 minutes and washed three times three minutes each in wash buffer. Slides were incubated in a dark humidified slide chamber in rabbit monoclonal anti-Ki67 antibody (1:50 dilution in 1\% BSA in wash buffer) for 2 hours at room temperature or overnight at $4^{\circ} \mathrm{C}$. A slide from an adjacent section was incubated in $1 \%$ BSA in wash buffer to use as negative control for staining. The slides were washed in wash buffer three times 5 minutes each after primary antibody incubation, followed by 30 minutes incubation (in dark and room temperature) in HRP Polymer (DAKO). Following three times wash 5 
minutes each in wash buffer, sections were blocked in DAB substrate-chromogen solution containing $1 \mathrm{ml}$ substrate buffer and 1 drop of DAB chromogen (DAKO) for 10 minutes followed by rising with $\mathrm{dH} 2 \mathrm{O}$ for 5 minutes. Slides were finally stained with 1:10 dilution of Harris Hematoxylin (Fisher Scientific) and washed in tap water for 10 minutes, followed by decolorization in $1 \%$ acid alcohol for 1 second and washing in tap water for 5 minutes. Slides were dehydrated in an ethanol series $(95 \%, 100 \%)$ and mounted with Permount (Fisher Scientific). The tumor sections were imaged at 32X magnification using a Nikon Coolpix 4500 camera mounted on a Zeiss Axiovert 100 bright field microscope.

\section{Image Quantification and Statistical Analysis of Ki-67}

Image quantification of Ki-67 stains were done using the ImageJ64 online program. Images were converted to 8-bit greyscale and the tumor field was outlined. In order to select total nuclei (the hematoxylin counterstained nuclei) in the field, a broad range threshold with a minimum value of 13 was applied to the image and the number of pixels from the threshold mask were recorded. The ratio of Ki-67 positive nuclei to total nuclei was calculated in Microsoft Excel using the recorded data. The mean and standard deviation was calculated for each tumor section. Three experimental replicates of Ki-67 stains were pooled for statistical analysis.

\section{Statistics}

Log-rank (Mantel-Cox) and Gehan-Breslow Wilcoxon statistical analyses was used to determine differences in tumour latency. Kruskal-Wallis followed by Mann- 
Whitney U Test was used to analyse tumour volumes. Statistical significance was assessed for immunohistochemistry using Kruskal-Wallis test with a Dunnett's post hoc analysis. Results were considered significant when $\mathrm{p}$ value was lower than $0.05(\mathrm{p}<$ $0.05)$.

\section{Results}

\section{Preparation and validation of a PRL secreting MCF7 cell line (MCF7hPRL)}

In order to create a xenograft model whereby the human breast cancer cells would have a consistent supply of human PRL, MCF7 cells were stably transfected with a human PRL expression (hPRL) plasmid or the empty vector (EV). Cellular PRL levels were evaluated from whole cell extracts. PRL levels were confirmed from 3 colonies (Colony 1, $3,5)$ and very low levels were detected from other two colonies, with no PRL detected in the parental MCF7 cell line (Figure 1A). PRL secretion from transfected colonies was evaluated from conditioned media (Figure 1B). PRL secretion was detected from the transfected colonies, using western blot. Colony 2 was similar to the parental MCF7 cell line with no PRL secretion detected. Two colonies (colony 1 and colony 5) shown to have relatively high levels of PRL (55 and 47ng/ml, respectively) and were pooled. The MCF7 control EV line was confirmed by amplification of the vector antibiotic (zeocin) resistance gene, Sh ble, in stable lines (Figure 1C). These syngeneic lines were used in subsequent experiments as a model for autocrine/paracrine secretion from breast cancer cells (MCF7hPRL) and its control line (MCF7EV). 
In order to confirm that the autocrine PRL successfully activates the PRLR of the transfected MCF7 cells, we examined phosphorylated-Stat5 (p-Stat5), versus total Stat5 levels, as a read-out of PRL-Jak2-Stat5 pathway activation in the parental MCF7, MCF7EV vector control and MCF7hPRL cells. Parental MCF7 and MCF7EV cells did not have detectable levels of p-STAT5 in the absence of PRL treatment, and demonstrated increased p-Stat5 levels with increasing concentrations of recombinant human PRL (25 $\mathrm{ng} / \mathrm{ml}, 50 \mathrm{ng} / \mathrm{ml}, 100 \mathrm{ng} / \mathrm{ml}$ and $150 \mathrm{ng} / \mathrm{ml}$ ) (Figure 1D), confirming that the recombinant human PRL can activate the Jak2 pathway. The MCF7hPRL cell line was shown to have similar levels of p-Stat5 with the parental cell lines treated with $50 \mathrm{ng} / \mathrm{ml}$ PRL concentration, which is consistent with their calculated daily PRL secretion. Therefore, the MCF7hPRL cell line was confirmed to secrete PRL and the secreted PRL activates the PRL-Jak2-Stat5 pathway as a readout of PRLR activation.

\section{Autocrine PRL delays tumour latency in the presence of DNA damage}

A novel orthotopic model of breast cancer was used to investigate the role of autocrine PRL and the DNA damage response on tumourigenicity and tumour volume. MCF7hPRL or control breast cancer cells were treated with the DNA damaging agent, 1 $\mu \mathrm{M}$ doxorubicin, and recovered for 48 hours. The dosage and length of treatment were based upon our previous work that demonstrated an active DNA damage response and specifically ATM phosphorylation (Karayazi Atici et al., 2018), and the cells were injected into the mammary fat pad of immune-deficient SCID mice. This model was used to test the hypothesis that PRL does not hinder the tumour-initiating ability of breast cancer cells. 
In order to test the effect of autocrine PRL in tumourigenicity, latency, and tumour size of breast cancer cells in the xenograft model, 500,000 MCF7hPRL or MCF7 control cells were injected into the number 4 mammary fat pad and monitored for 60 days. Tumour formation was observed as early as 10 days in mice injected with 500,000 MCF7hPRL cells or doxorubicin-treated MCF7 cells, and was followed by tumour formation in mice injected with MCF7 control cells at 15 days. Eighty percent of mice carrying MCF7hPRL or MCF7 control cells formed a palpable tumour by 20 days post injection, and $80 \%$ of mice injected with doxorubicin-treated MCF7 cells formed a palpable tumour at day 30 (Figure 2A)., Only one mouse, however, formed a palpable tumour when injected with doxorubicin-treated MCF7hPRL cells on day 25, and no other detectable tumour formation was observed over 60 days in this group. The three groups, vehicle control, hPRL or doxorubicin treated, were indistinguishable from each other statistically, however there was statistically significant difference between the mice injected with MF7hprl cells and the mice injected with doxorubicin-treated MCF7hPRL cells (Log-rank p=0.039, GehanBreslow Wilcoxon $\mathrm{p}=0.0282$ ). Therefore, there was a longer latency to tumour formation for PRL-secreting, doxorubicin-treated MCF7hPRL cells.

According to the trend seen from the tumour volume graphs (Figure 2B), mice injected with MCF7 control and MCF7hPRL cells had the largest tumours, The mice injected with doxorubicin-treated MCF7 and doxorubicin-treated MCF7hPRL cells formed smaller tumours. 


\section{Tumour initiation is delayed with PRL and DNA damage but not prevented}

In order to provide an opportunity to observe if the apparent protective effect would extend over time, we repeated the above experiment, but reduced the number of injected cells from 500,000 to 250,000 , and the increased the observation days to 120 days. According to the results for the latency to tumour formation, MCF7hPRL injected mice formed palpable mammary tumours starting from day 10 after cell injection, $80 \%$ of the mice in this group formed a tumour within 35 days and $100 \%$ by 100 days (Figure 2C). The group of mice injected with MCF7 control cells had similar results, in that early tumour formation was detected at 10 days post cell injection, with $80 \%$ of the mice in this group formed a tumour within 50 days and 100\% within 65 days post cell injection (Figure 2C). The latency to tumour formation was longer in the group injected with doxorubicin-treated MCF7 cells, such that although early tumour formation started around 10 days after cell injection, $80 \%$ of the group formed a tumour only over 60 days, and $100 \%$ by 120 days (Figure 2C). Consistent with first experiment, increased latency was also observed in the mice injected with doxorubicin-treated MCF7hPRL cells, as tumour formation started 20 days post cell injection, only $40 \%$ of the mice formed a tumour over 60 days (Figure 2C), and all the animals acquired a tumour in the group by the end of the experimental time (120 days) (Figure 2C). There was statistical difference between the group of mice injected with MCF7hPRL and doxorubicin-treated MCF7hPRL cells at 60 days (Log-rank $p=0.0419$, Gehan-Breslow Wilcoxon $\mathrm{p}=0.039$ ) (Figure 2C). The latency to tumour formation was increased in mice injected with doxorubicin-treated MCF7hPRL cells but was not permanent. 
The tumour volume measurements demonstrated a trend that MCF7 cells formed the largest tumours, followed by MCF7hPRL, doxorubicin-treated MCF7 cells. The tumours generated by doxorubicin-treated MCF7hPRL cells were very small in volume (Figure 2D), consistent with the previous experiment. According to the data analysis using Kruskal-Wallis ANOVA and Mann-Whitney U Tests, there was a statistical difference $(\mathrm{p}=0.009)$ between tumours formed with MCF7 control cells and doxorubicin-treated MCF7hPRL cells at the 120-day endpoint (Figure 2D).

Overall, we observed that latency to tumour formation was significantly delayed in MCF7hPRL cells treated with doxorubicin in SCID mice, although the protection was not permanent, and resulted in the smallest tumours at the end of the experiment.

\section{Doxorubicin treatment reduces tumour cell proliferation}

In order to investigate the effects on cell proliferation in vivo, the xenograft tumors were investigated by immunohistochemistry analysis using Ki-67 as a proliferation marker (Figure 3A). Tumours formed from MCF7 control or MCF7hprl cells had the highest proliferative index, followed by tumors formed from doxorubicin-treated MCF7 control cells and doxorubicin-treated MCF7hprl cells (Figure 3B). According to the statistical analysis (Tukey's test), tumors formed with doxorubicin-treated MCF7hprl cells had the lowest proliferative index when compared with tumors formed with MCF7 control cells $(\mathrm{p}=0.029)$ and MCF7hprl $(\mathrm{p}=0.02)$. Therefore, PRL alone did not have a negative impact on tumour formation, but doxorubicin reduced cell proliferation in vivo. 


\section{Autocrine PRL and DNA Damage response attracts asialo-GM1 positive immune cells in SCID mice}

In order to determine if the reason for delayed latency to tumour formation in the MCF7hPRL cells with doxorubicin-induced DNA damage was due in part to increased activity or presence of immune cells, such as NK cells, we assessed the involvement of asialo-GM1 positive immune cells in the mechanism. We used the same animal model, with 500,000 cells in each group of MCF7 control or MCF7hPRL cells injected into SCID mice. Cells were treated or not for 2 hours with doxorubicin ( $1 \mathrm{mM})$ followed by 48 hours recovery time in the absence of doxorubicin prior to injection. Mice were injected with anti-asialo-GM1 antibody or control serum from the start of the experiment to address the effect on tumour initiation.

Importantly, anti-asialo-GM1 injection did not show any effect on the mice injected with doxorubicin-treated MCF7 control cells when compared with mice injected with control serum (Figure 4A). Tumour formation was observed 10 days after cell injection in the group of mice injected with MCF7hPRL cells, also independent of anti-asialo-GM1 (Figure 4B). Tumour formation was, however, impacted when the MCF7hPRL cells were treated with doxorubucin. As expected, tumour formation of doxorubicin-treated MCF7hPRL cells was delayed in the animals injected with control serum until day 25, however tumour formation occurred much earlier on day 10 in the mice injected with antiasialo GM1 antibody. (Figure 4C). Therefore, combined PRL and doxorubicin treatments result in delayed tumour initiation of breast cancer cells due largely to the action of asialoGM1-positive immune cells. 
The mice injected with doxorubicin-treated MCF7hPRL or MCF7 control cells had a trend to form the smallest tumours in both control serum and anti-asialo-GM1 injected groups (Figure 4D). Mice injected with MCF7hPRL cells had the largest tumours, independent of injection with anti-asialo GM1 antibody (Figure 4E). There was a significant decrease in tumour volume $(\mathrm{p}=0.03)$ when doxorubicin treated MCF7hPRL cells were exposed to anti-asialo-GM1 (Figure 4E). The combination of doxorubicin and PRL resulted in smaller tumours, but the effect of the anti-asialo-GM1 antibody appeared to have a greater role in early tumour formation rather than at the experimental endpoint. The increased presence and/or activity of asialo-GM1-positive cells stimulated by breast cancer cells responding to PRL and DNA damage impacts early tumour formation, but not tumour volume by the end of the experimental time.

\section{Discussion}

In our breast cancer recurrence model, we have demonstrated that PRL in the tumour microenvironment does not delay tumour initiation, but in the context of the DNA damage response, combined PRL signaling with DNA damage leads to immune cell attack and increase latency of tumour formation. These observations may clarify conflicting reports of the role of PRL in breast cancer tumorigenesis and tumour progression.

The role of autocrine PRL in tumour biology has been previously studied in three different animal models. Production of PRL under control of the metallothionein gene promoter in transgenic mice resulted in mammary tumour formation in $100 \%$ of the females (Wennbo et al., 1997). In a transgenic mice model that overexpresses PRL within 
mammary epithelial cells, under control of the neu-related lipocalin NRL promoter (Arendt and Schuler, 2008), autocrine PRL was demonstrated to induce mammary tumours in NRLPRL transgenic mice (Arendt et al., 2011, Rose-Hellekant et al., 2003). In a study from Liby and colleagues (Liby et al., 2003), MDA-MB-435 cells, whose origin is now known to be melanoma (Korch et al., 2018), were genetically engineered to overexpress PRL and the cells were injected into mammary fat pad of nude mice. PRL secreting cells were shown to increase tumour growth 2-4-fold when compared with parental MDA-MB-435 cells. Additionally, tumours formed with PRL-secreting cells were demonstrated to metastasize to the lymph nodes. PRL was overall shown to promote tumour initiation, tumour growth and metastasis in in vivo models.

PRLR function in tumour progression or metastasis has also been studied in vivo via delivery of recombinant PRL to animal models. Tumours generated in mice using 7,12Dimethylbenz $[\alpha]$ anthracene (DMBA) regressed with the PRLR antagonist, LFA102, a humanized neutralizing monoclonal antibody directed against the extracellular domain of PRLR (Damiano et al., 2013). Using a splice modulating oligomer that knocked down only the long PRLR form in vivo, the long PRLR form was shown to be responsible for lung and liver metastasis and cell survival in primary mammary syngeneic tumours of 4T1 cells and BT-474 xenografts in in vivo models of breast cancer (Yonezawa et al., 2015). Overall, these models indicate that PRL and the PRLR support breast tumour progression and metastasis.

In our xenograft model, the autocrine PRL-secreting breast cancer cells or control cells were pre-treated with doxorubicin or vehicle and injected into the mammary fat pad of SCID mice, and the tumorigenicity and tumour volume were observed over time. The 
doxorubicin pre-treated PRL-secreting cells formed tumors later when compared with control, PRL-secreting, or doxorubicin-only treated cells. The tumor volumes were also of smaller size in the PRL and doxorubicin-treated group. In the immune deficient SCID mice used in this study, T and B cells are deficient, however NK cells, macrophages and basophils are present. In order to investigate the mechanism and the effect of microenvironment on tumorigenicity we used the anti-asialo GM1 antibody, traditionally used to deplete NK cells. The anti-asialo GM1 antibody shortened the time to tumour formation of doxorubicin pre-treated PRL-secreting cells, which implicated that the combination of PRL secretion and DNA damage attracts immune cells that interfere with tumour initiation and/or progression.

In a conflicting report, PRL was observed to suppress tumorigenicity of triple negative breast cancers cells in the non-obese diabetic NOD/SCID mouse xenograft model. The NOD-SCID model has a deficiency in T and B cells and reduced NK cell activity (Kataoka S., 1983). MDA-MB-231 triple negative breast cancer cells were stably engineered to express the long form PRLR using a doxycycline dependent expression system (Lopez-Ozuna, 2019). Both doxycycline and PRL were provided simultaneously at the time of tumour formation in this inducible model. We speculate that the observed PRLmediated reduction of tumour growth might be due to a small population of anti-asialo GM1 immune cells activated by combination of PRL and accumulated DNA damage from doxycycline (Peiris-Pagès, 2015) . Alternatively, the PRLR-transduced MDA-MB-231 cell line may be the biological difference resulting in their observations.

We previously demonstrated ATM was required for PRL-JAK2-STAT5-induced clonogenic survival and cell viability after DNA damage from doxorubicin (Karayazi Atici 
et al., 2018). We did not observe greater tumour size in this in vivo setting due to the action of asialo-GM1-positive immune cell components in the tumour microenvironment in the presence of both PRL and DNA damage. We hypothesize that the in vivo mechanism that triggers immune cell attack also involves the cross-talk of the PRL and DNA damage response pathways in breast cancer cells.

The anti-asialo antibody was designed to deplete NK cells. Recent studies have discovered that the anti-asialo-GM1 antibody can also target basophil cells (Nishikado et al. 2011), NK, NKT, CD8+T, $\gamma \delta T$, some CD4+T cells, macrophages, and eosinophils (Kataoka S., 2004, Slifka et al., 2000, Trambley et al., 1999, Nishikado et al., 2011, Wiltrout RH, 1985). Although SCID mice do not have functional B or T cells, they do have functional NK cells, macrophage, eosinophils and basophils (Dorshkind, 1985), of which NK cells (Yang Q., 2006), eosinophils (R.I, 1994) and basophils (Sektioglu et al., 2017) have been implicated to have anti-tumor activity.

NK cells are cytotoxic lymphocytes of innate immune system and have a critical role in immune response to tumours and viral infections. DNA damage has been demonstrated to activate several ligands specific for NK cell receptors (reviewed in (Chan et al., 2014). Chemotherapeutic agent induced cellular stress and DNA damage response do attract NK cells (Soriani et al., 2014, Raulet and Guerra, 2009, Raulet et al., 2013) and increase ligand expression of NK cell receptors such as NK2GD and DNAM-1 in ATM and ATR dependent manner (Soriani, 2009). Doxorubicin mediated DNA damage was shown to increase NK cells and T cell mediated killing of tumor cells in a mechanism that involves TRAIL receptor signaling (Wennerberg et al., 2013). 
PRL has been implicated to have an important role in the recruitment of immune cells to the mammary gland. PRL treatment of adult female black 6 mice increased lymphocyte number in the mammary gland. Experiments with normal mammary HC11 cells in vitro revealed that PRL increased the migration of B cells, CD4+ T cells, CD4+ memory T cells, CD8+ memory cells, macrophages, monocytes, neutrophils eosinophils (Dill and Walker, 2017) and basophils (Nishikado et al. 2011, Freeman et al., 2000). It was not reported if PRL recruited NK cells to mammary epithelial cells. PRL was also shown to directly improve the antitumor effects of NK cells in Balb/c and SCID mice that NK cells respond to PRL via their PRLR (Sun R., 2004, Sun R., 2002). PRL has been shown to directly upregulate the NK major receptors involved in lytic cell death (Mavoungou et al., 2005).

In summary, we observed that PRL supports tumour formation, but that PRL in combination with the DNA damage response, temporarily increases tumour latency of breast cancer cells in an orthotopic xenograft model in a mechanism that involves asialoGM1-expressing immune cells. This may have implications for the use of PRLR antagonists during anti-cancer treatment with doxorubicin.

\section{Acknowledgements}

This research was made possible by grants made to CSS from the Alberta Cancer Foundation and the Canadian Cancer Foundation. CSS was responsible for study conception and design; CSS and OKA for analysis and interpretation of data, writing and revision of manuscript; OKA for acquisition of data; Colin Stewart contributed technical assistance to part of the study. Thank you to Isbel Lopetegui González for critical reading of this manuscript. 


\section{References}

ARENDT, L. M., RUGOWSKI, D. E., GRAFWALLNER-HUSETH, T. A., GARCIABARCHINO, M. J., RUI, H. \& SCHULER, L. A. 2011. Prolactin-induced mouse mammary carcinomas model estrogen resistant luminal breast cancer. Breast Cancer Res, 13, R11.

ARENDT, L. M. \& SCHULER, L. A. 2008. Transgenic models to study actions of prolactin in mammary neoplasia. J Mammary Gland Biol Neoplasia, 13, 29-40.

BEN-JONATHAN, N., MERSHON, J. L., ALLEN, D. L. \& STEINMETZ, R. W. 1996. Extrapituitary prolactin: distribution, regulation, functions, and clinical aspects. Endocr Rev, 17, 639-69.

CHAN, C. J., SMYTH, M. J. \& MARTINET, L. 2014. Molecular mechanisms of natural killer cell activation in response to cellular stress. Cell Death Differ, 21, 5-14.

DAMIANO, J. S., RENDAHL, K. G., KARIM, C., EMBRY, M. G., GHODDUSI, M., HOLASH, J., FANIDI, A., ABRAMS, T. J. \& ABRAHAM, J. A. 2013.

Neutralization of prolactin receptor function by monoclonal antibody LFA102, a novel potential therapeutic for the treatment of breast cancer. Mol Cancer Ther, 12, 295-305.

DILL, R. \& WALKER, A. M. 2017. Role of Prolactin in Promotion of Immune Cell Migration into the Mammary Gland. J Mammary Gland Biol Neoplasia, 22, 1326.

DORSHKIND, K., POLLACK ,S.B, BOSMA, M.J., PHILIPS, R.A. 1985. Natural Killer (NK) cells are present in mice with severe combined immunodeficiency (scid) The Journal of Immunology, 134, 3798-3801.

FAUSTINO-ROCHA, A., OLIVEIRA, P. A., PINHO-OLIVEIRA, J., TEIXEIRAGUEDES, C., SOARES-MAIA, R., DA COSTA, R. G., COLACO, B., PIRES, M. J., COLACO, J., FERREIRA, R. \& GINJA, M. 2013. Estimation of rat mammary tumor volume using caliper and ultrasonography measurements. Lab $\operatorname{Anim}(N Y), 42,217-24$.

HORSEMAN, N. D., ZHAO W, MONTECINO-RODRIGUEZ E, TANAKA M, NAKASHIMA K, ENGIE SJ, SMITH F, MARKOFF E, DORSHKIND K 1997. Defective mammopoiesis, but normal hematopoiesis, in mice with a targeted disruption of the prolactin gene EMBO J, 16, 6926-35.

HOWELL, S. J., ANDERSON, E., HUNTER, T., FARNIE, G. \& CLARKE, R. B. 2008. Prolactin receptor antagonism reduces the clonogenic capacity of breast cancer cells and potentiates doxorubicin and paclitaxel cytotoxicity. Breast Cancer Res, 10, R68.

IDELMAN, G., JACOBSON, E. M., TUTTLE, T. R. \& BEN-JONATHAN, N. 2011. Lactogens and estrogens in breast cancer chemoresistance. Expert Rev Endocrinol Metab, 6, 411-422.

KARAYAZI ATICI, O., URBANSKA, A., GOPINATHAN, S. G., BOUTILLON, F., GOFFIN, V.\& SHEMANKO, C. S. 2018. ATM Is Required for the ProlactinInduced HSP90-Mediated Increase in Cellular Viability and Clonogenic Growth After DNA Damage. Endocrinology, 159, 907-930. 
KATAOKA S., K. Y., NISHIO Y., FUJIKAWA-ADACHI K., TOMINAGA A 2004. Antitumor Activity of Eosinophils Activated by IL-5 and Eotaxin against Hepatocellular Carcinoma DNA and Cell Biology 23, 549-560.

KATAOKA S., S. J., FUJIYA H., TOYOTA T., SUZUKI R., ITOH K., KUMAGAI K. 1983. Immunologic Aspects of the Nonobese Diabetic (NOD) Mouse: Abnormalities of Cellular Immunity Diabetes 32, 247- 253.

KORCH, C., HALL, E. M., DIRKS, W. G., EWING, M., FARIES, M., VARELLAGARCIA, M., ROBINSON, S., STORTS, D., TURNER, J. A., WANG, Y., BURNETT, E. C., HEALY, L., KNISS, D., NEVE, R. M., NIMS, R. W., REID, Y. A., ROBINSON, W. A. \& CAPES-DAVIS, A. 2018. Authentication of M14 melanoma cell line proves misidentification of MDA-MB-435 breast cancer cell line. Int J Cancer, 142, 561-572.

LAPENSEE, E. W. \& BEN-JONATHAN, N. 2010. Novel roles of prolactin and estrogens in breast cancer: resistance to chemotherapy. Endocr Relat Cancer, 17, R91-107.

LIBY, K., NELTNER, B., MOHAMET, L., MENCHEN, L . \& BEN-JONATHAN, N. 2003. Prolactin overexpression by MDA-MB-435 human breast cancer cells accelerates tumor growth. Breast Cancer Res Treat, 79, 241-52.

LOPEZ-OZUNA, V. M., HACHIM, I.Y., HACHIM, M.Y., LEBRUN, J.J., ALI, S. 2019. Prolactin Modulates TNBC Aggresive Phenotype Limiting Tumorigenesis Endocr Relat Cancer, 26, 321-337.

MAVOUNGOU, E., BOUYOU-AKOTET, M. K. \& KREMSNER, P. G. 2005. Effects of prolactin and cortisol on natural killer (NK) cell surface expression and function of human natural cytotoxicity receptors (NKp46, NKp44 and NKp30). Clin Exp Immunol, 139, 287-96.

MILLER, S. L., ANTICO, G., RAGHUNATH, P. N., TOMASZEWSKI, J. E. \& CLEVENGER, C. V. 2007. Nek3 kinase regulates prolactin-mediated cytoskeletal reorganization and motility of breast cancer cells. Oncogene, 26, 4668-78.

MILLER, S. L., DEMARIA, J. E., FREIER, D. O., RIEGEL, A. M. \& CLEVENGER, C. V. 2005. Novel association of Vav2 and Nek3 modulates signaling through the human prolactin receptor. Mol Endocrinol, 19, 939-49.

MUTHUSWAMY, S. K. 2012. Autocrine prolactin: an emerging market for homegrown (prolactin) despite the imports. Genes Dev, 26, 2253-8.

NISHIKADO, H., MUKAI, K., KAWANO, Y., MINEGISHI, Y . \& KARASUYAMA, H. 2011. NK cell-depleting anti-asialo GM1 antibody exhibits a lethal off-target effect on basophils in vivo. J Immunol, 186, 5766-71.

O'LEARY, K. A., SHEA, M. P. \& SCHULER, L. A. 2015. Modeling prolactin actions in breast cancer in vivo: insights from the NRL-PRL mouse. Adv Exp Med Biol, 846, 201-20.

PEIRIS-PAGÈS, M., FEDERICA, S., LISANTI, M.P. 2015. Doxycycline and therepeutic targeting of DNA damage response in cancerl cells: old drug, new purpose Oncoscience 2, 696-699.

PERKS, C. M., KEITH, A. J., GOODHEW, K. L., SAVAGE, P. B., WINTERS, Z. E. \& HOLLY, J. M. 2004. Prolactin acts as a potent survival factor for human breast cancer cell lines. Br J Cancer, 91, 305-11. 
PEROTTI, C., KARAYAZI, O., MOFFAT, S. \& SHEMANKO, C. S. 2012. The bone morphogenetic protein receptor-1A pathway is required for lactogenic differentiation of mammary epithelial cells in vitro. In Vitro Cell Dev Biol Anim, 48, 377-84.

PEROTTI, C., LIU, R., PARUSEL, C., BÖCHER, N., SCHULTZ, J., BORK, P., PFITZNER, E., GRONER, B. \& SHEMANKO, C. S. 2008. Heat shock protein 90alpha (Hsp90alpha), a prolactin-Jak2-Stat5 target gene identified in breast cancer cells, is involved in apoptosis regulation. Breast Cancer Research, 10, R94.

R.I, T. 1994. The eosinophil-mediated antitumor activity of interleukin-4. J Allergy Clin Immunol 94.

RAULET, D. H., GASSER, S., GOWEN, B. G., DENG, W. \& JUNG, H. 2013. Regulation of ligands for the NKG2D activating receptor. Annu Rev Immunol, 31, 413-41.

RAULET, D. H. \& GUERRA, N. 2009. Oncogenic stress sensed by the immune system: role of natural killer cell receptors. Nat Rev Immunol, 9, 568-80.

ROSE-HELLEKANT, T. A., ARENDT, L. M., SCHROEDER, M. D., GILCHRIST, K., SANDGREN, E. P. \& SCHULER, L. A. 2003. Prolactin induces ERalphapositive and ERalpha-negative mammary cancer in transgenic mice. Oncogene, 22, 4664-74.

SEKTIOGLU, I. M., CARRETERO, R., BULBUC, N., BALD, T., TUTING, T., RUDENSKY, A. Y. \& HAMMERLING, G. J. 2017. Basophils Promote Tumor Rejection via Chemotaxis and Infiltration of CD8+ T Cells. Cancer Res, 77, 291302.

SHEMANKO, C. S. 2016. Prolactin receptor in breast cancer: marker for metastatic risk. J Mol Endocrinol, 57, R153-R165.

SLIFKA, M. K., PAGARIGAN, R. R. \& WHITTON, J. L. 2000. NK Markers Are Expressed on a High Percentage of Virus-Specific CD8+ and CD4+ T Cells. The Journal of Immunology, 164, 2009-2015.

SORIANI, A., IANNITTO, M. L., RICCI, B., FIONDA, C., MALGARINI, G., MORRONE, S., PERUZZI, G., RICCIARDI, M. R., PETRUCCI, M. T., CIPPITELLI, M. \& SANTONI, A. 2014. Reactive oxygen species- and DNA damage response-dependent NK cell activating ligand upregulation occurs at transcriptional levels and requires the transcriptional factor E2F1. J Immunol, 193, 950-60.

SORIANI, A., ZINGONI, A., CERBONI, C., IANNITTO, M.L., RICCLARDI, M.R. ET AL. 2009. ATM-ATR-dependent up-regulation of DNAM-1 and NKG2D ligands on multiple myloma cells by therapeutic agents results in enhanced NK-cell susceptibility and is associated with a senescent phenotype Blood, 113, 35033511.

SUN R., L. A. L., WEI H.M., TIAN Z.G. 2004. Expression of prolactin receptor and response to prolactin stimulation of human NK cells Cell Research 14, 67-73.

SUN R., W. H., ZHANG J., LI A., ZHANG W., TIAN Z.G. 2002. Recombinant human prolactin improves antitumor effecst of murine natural killer cells in vitro and in vivo Neuroimmunomodulation, 10, 169-176. 
SUTHERLAND, A., FORSYTH, A., CONG, Y., GRANT, L., JUAN, T. H., LEE, J. K., KLIMOWICZ, A., PETRILLO, S. K., HU, J., CHAN, A., BOUTILLON, F., GOFFIN, V., EGAN, C., TANG, P. A., CAI, L., MORRIS, D., MAGLIOCCO, A. \& SHEMANKO, C. S. 2016. The Role of Prolactin in Bone Metastasis and Breast Cancer Cell-Mediated Osteoclast Differentiation. J Natl Cancer Inst, 108, djv338.

TRAMBLEY, J., BINGAMAN, A. W., LIN, A., ELWOOD, E. T., WAITZE, S. Y., HA, J., DURHAM, M. M., CORBASCIO, M., COWAN, S. R., PEARSON, T. C. \& LARSEN, C. P. 1999. Asialo GM1(+) CD8(+) T cells play a critical role in costimulation blockade-resistant allograft rejection. J Clin Invest, 104, 1715-22.

WENNBO, H., GEBRE-MEDHIN, M., GRITLI-LINDE, A., OHLSSON, C., ISAKSSON, O. G. \& TORNELL, J. 1997. Activation of the prolactin receptor but not the growth hormone receptor is important for induction of mammary tumors in transgenic mice. J Clin Invest, 100, 2744-51.

WENNERBERG, E., SARHAN, D., CARLSTEN, M., KAMINSKYY, V. O., D'ARCY, P., ZHIVOTOVSKY, B., CHILDS, R. \& LUNDQVIST, A. 2013. Doxorubicin sensitizes human tumor cells to NK cell- and T-cell-mediated killing by augmented TRAIL receptor signaling. Int J Cancer, 133, 1643-52.

WILTROUT RH, S. A., PETERSON ES, KNOTT DC, OVERTON WR, ET AL 1985. Reactivity of anti-asialo GM1 serum with tumouricidal and non-tumouricidal mouse macrophages. Journal of leukocyte biology 37, 597-614.

YAMAUCHI, T., YAMAUCHI, N., UEKI, K., SUGIYAMA, T., WAKI, H., MIKI, H., TOBE, K., MATSUDA, S., TSUSHIMA, T., YAMAMOTO, T., FUJITA, T., TAKETANI, Y., FUKAYAMA, M., KIMURA, S., YAZAKI, Y., NAGAI, R. \& KADOWAKI, T. 2000. Constitutive Tyrosine Phosphorylation of ErbB-2 via Jak2 by Autocrine Secretion of Prolactin in Human Breast Cancer. J Biol Chem, 275, 33937-33944.

YANG Q., G. S. R., HOKLAN M.E., BASSE P.H. 2006. Antitumor activity of NK cells. Immunologic Research 36/1, 13-25.

YONEZAWA, T., CHEN, K. H., GHOSH, M. K., RIVERA, L., DILL, R., MA, L., VILLA, P. A., KAWAMINAMI, M. \& WALKER, A. M. 2015. Anti-metastatic outcome of isoform-specific prolactin receptor targeting in breast cancer. Cancer Lett, 366, 84-92. 


\section{Figure Legends}

Figure 1: Engineering of PRL-secreting and control lines. A. PRL levels measured from whole cell extraction of MCF7 parental cells and MCF7hPRL colonies. GRB2 was used as a loading control. B. Western analysis of PRL secretion from MCF7hPRL colonies quantified with Image J using human recombinant PRL standard. C. PCR data showing Sh ble zeocin resistance gene from MCF7hPRL and MCF7 control (EV) colonies. YHWAZ was used as house-keeping gene. D.p-Stat5 and total Stat5 and Histone-H3 (loading control) levels from untreated MCF7hPRL cells, or parental MCF7 and MCF7 control (EV) cells treated with increasing concentrations of human PRL.

Figure 2. Autocrine PRL delays tumour latency in the presence of DNA damage in

SCID mice. A. Tumour latency in SCID mice after injection of 500,000 MCF7 or MCF7hPRL cells untreated or treated with doxorubicin (MCF7+dox or MCF7hPRL+dox) over 60 days. B. Comparison of accumulated tumour volumes between treatment groups over 60 days. C. Tumour latency in SCID mice after injection of 250,000 MCF7 or MCF7hPRL cells untreated or treated with doxorubicin (MCF7+dox or MCF7hPRL+dox) over 120 days. D. Comparison of accumulated tumour volumes between treatment groups over 120 days. Sample size is $n=5$ for each group. Log-rank (Mantel-Cox) and Gehan-Breslow Wilcoxon tests were used for statistical analysis. Tumour volumes were tested using Kruskal-Wallis ANOVA followed by Mann-Whitney U tests. 
Figure 3: Proliferation index of xenograft tumours. A. Ki-67 immunohistochemistry on primary xenograft tumours assessing the role of autocrine PRL on cell proliferation. The upper panels are images from sections incubated with 1\% BSA (negative control). The lower panes are incubated with 1:50 anti-rabbit- Ki-67 antibody. Ki-67 was detected with HRP-DAB immunohistochemistry (brown) and nuclear hematoxylin counterstain (light purple). The sections were imaged at $32 \mathrm{X}$ magnification using a Nikon Coolpix 4500 camera mounted on a Zeiss Axiovert 100 bright field microscope, scale bars $=0.1$ mm. B. Quantification of Ki-67 index. The mean ratio of Ki-67 positive nuclei for three experiments were compared between MCF7, MCF7hPRL, MCF7+dox, MCF7hPRL+dox injected experimental groups. In each experiment, between 3-16 fields were imaged and analyzed-representing the entire tumour section. Values represent the mean of three tumours. Error bars represent standard deviation. Tukey's test, $* \mathrm{p}<0.05$ between MCF7hPRL+dox and MCF7 or MCF7hPRL.

Figure 4. Autocrine PRL and DNA Damage response in breast cancer cells attracts anti-asialo GM1 immune cells in SCID mice A. Tumour latency after injection of doxorubicin treated MCF7 Control cells and anti-asialo GM1 (MCF7+dox+AA GM1) or control serum (MCF7+dox+CS). B. Tumour latency after injection of MCF7hPRL cells and anti-asialo GM1 (MCF7hPRL+AA GM1) or control serum (MCF7hPRL+CS). C Tumour latency after injection of doxorubicin treated MCF7hPRL cells and anti-asialo GM1 (MCF7hPRL+dox+AA GM1) or control serum (MCF7hPRL+dox+CS). Log-rank (Mantel-Cox) and Gehan-Breslow Wilcoxon tests were used for statistical analysis. D. Comparison of tumour volumes between treatment 
groups after injection of doxorubicin treated MCF7 cells and anti-asialo GM1 (MCF7

Control+dox+AA GM1) and control serum (MCF7+dox+CS) . E. Comparison of tumour volumes between treatment groups after injection of untreated or doxorubicin treated MCF7hPRL cells and anti-asialo GM1 and control serum (MCF7hPRL+CS, MCF7hPRL+AA GM1, MCF7hPRL+dox+CS, MCF7hPRL+dox+AA GM1). Tumour volumes were tested using Kruskal-Wallis ANOVA followed by Mann-Whitney U tests. Sample size $n=5$ per group. 


\section{Table 1 Primers}

\begin{tabular}{|l|l|l|l|}
\hline Primer name & Primers & $\begin{array}{l}\text { Tm } \\
\left({ }^{\mathbf{C}} \mathbf{C}\right)\end{array}$ & $\begin{array}{l}\text { Expected } \\
\text { amplicon } \\
\text { size (pb) }\end{array}$ \\
\hline $\begin{array}{l}\text { Steptoalloteichus } \\
\text { hindustanus bleomycin } \\
\begin{array}{l}\text { (Sh-ble) (Zeocin resistance } \\
\text { gene) }\end{array}\end{array}$ & $\begin{array}{l}\text { F- 5'-AAGTTGACCAGTGCCGTTCC-3' } \\
\text { R- 5'-CTCCTCGGCCACGAAGTG-3' }\end{array}$ & $60^{\circ} \mathrm{C}$ & 360 \\
\hline $\begin{array}{l}\text { Tyrosine 3- } \\
\text { monooxygenase/tryptophan } \\
\text { 5-monooxygenase } \\
\text { activation protein } \\
\text { (YWHAZ) }\end{array}$ & $\begin{array}{l}\text { F- 5'-AGTCGTACAAAGACAGCACGTAA- } \\
\text { R-5'-AGGCAGACAAAGGTTGGAAGG-3' }\end{array}$ & $60^{\circ} \mathrm{C}$ & 138 \\
\hline
\end{tabular}


Figure 1

A

\begin{tabular}{|c|c|c|c|c|c|c|}
\hline \multirow[b]{2}{*}{ MCF7 } & \multicolumn{5}{|c|}{ MCF7hPRL colonies } & \\
\hline & 1 & 2 & 3 & 4 & 5 & \\
\hline & $m$ & & - & & 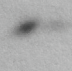 & PRL (25kDa) \\
\hline$\infty$ & $=$ & - & - & - & $\sim$ & GRB2 (25kDa) \\
\hline
\end{tabular}

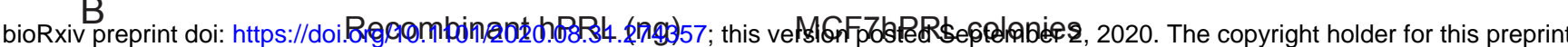

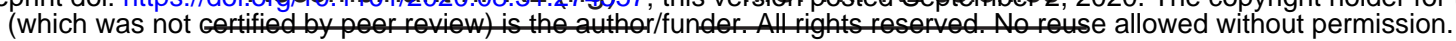

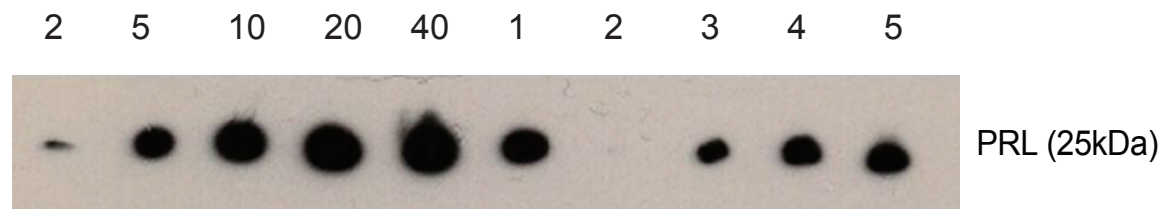

C

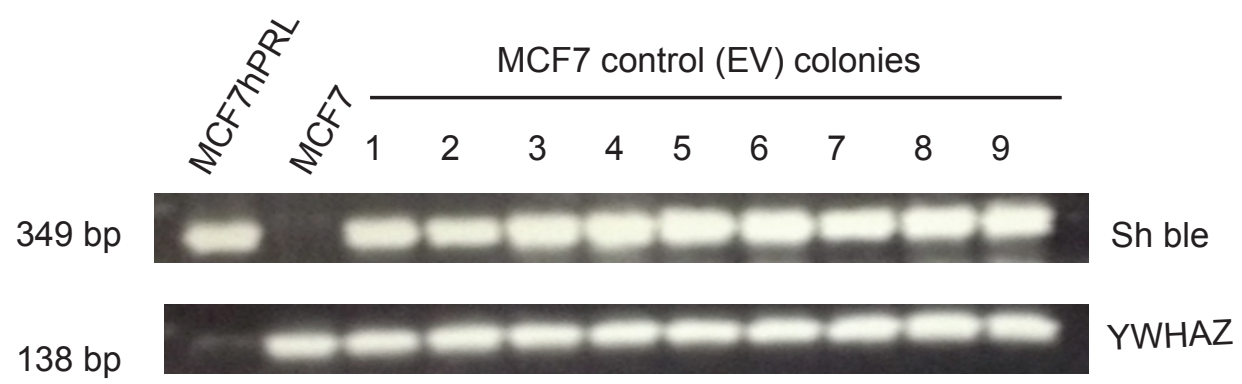

D

\section{MCF7}

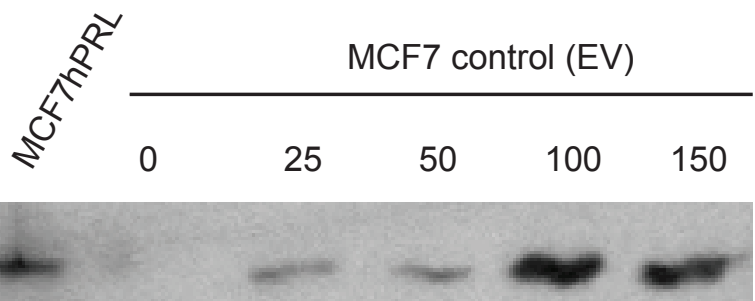

p-Stat5 (92 kDa)

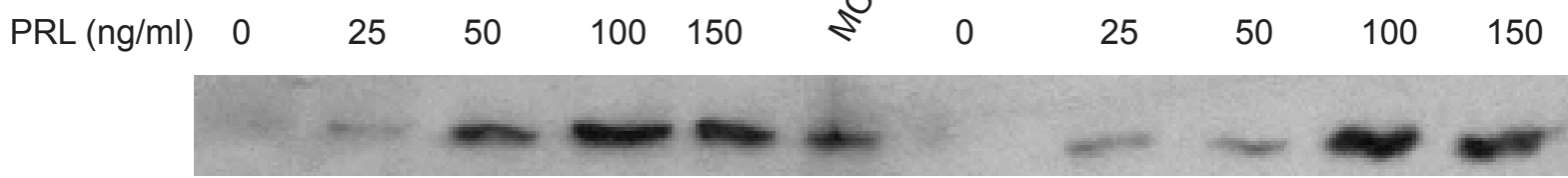

Stat5 (92 kDa)

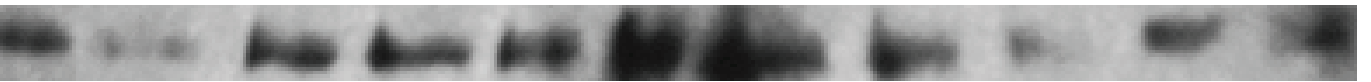

Histone H3 (17 kDa) 
A

Figure 2
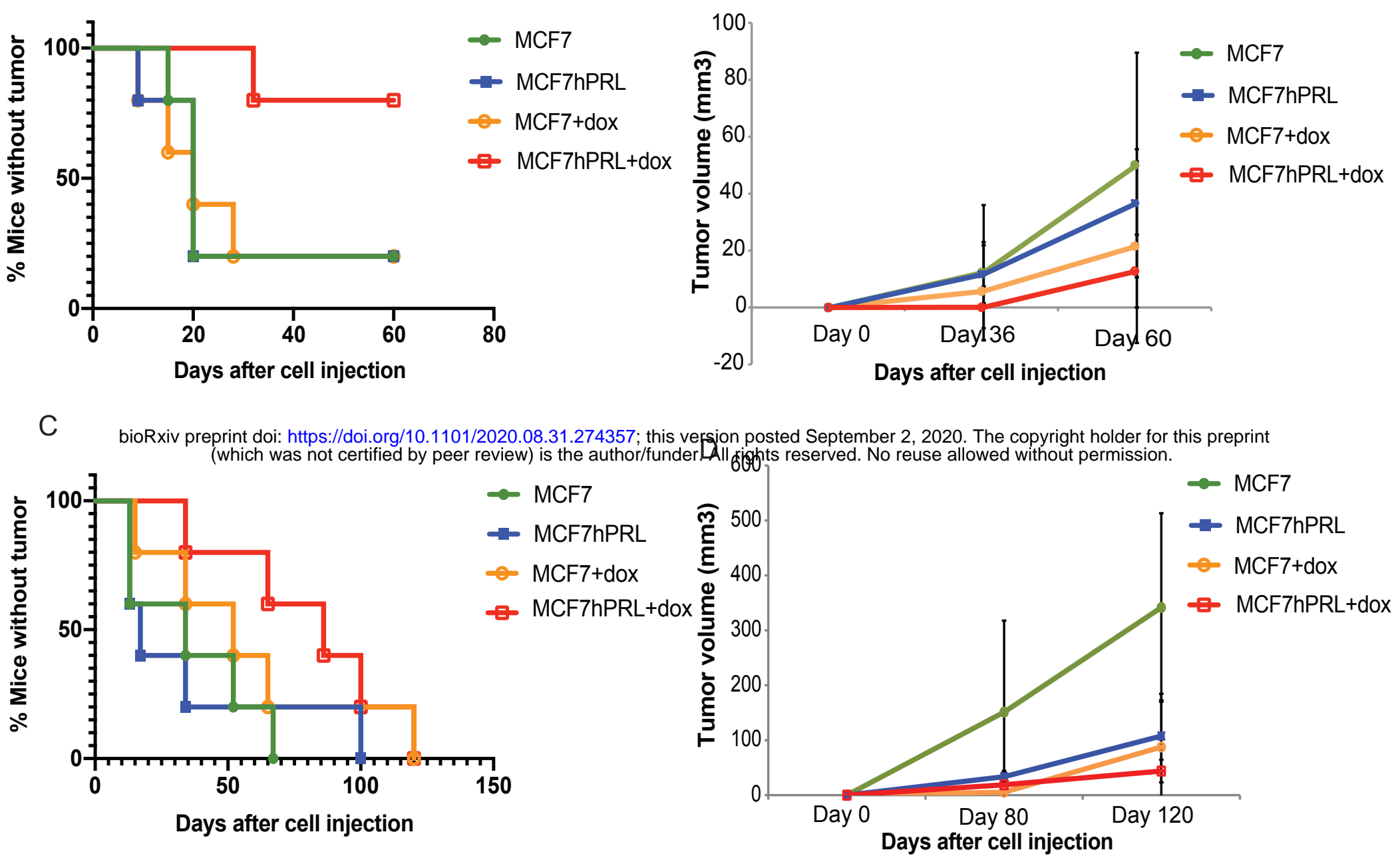
A

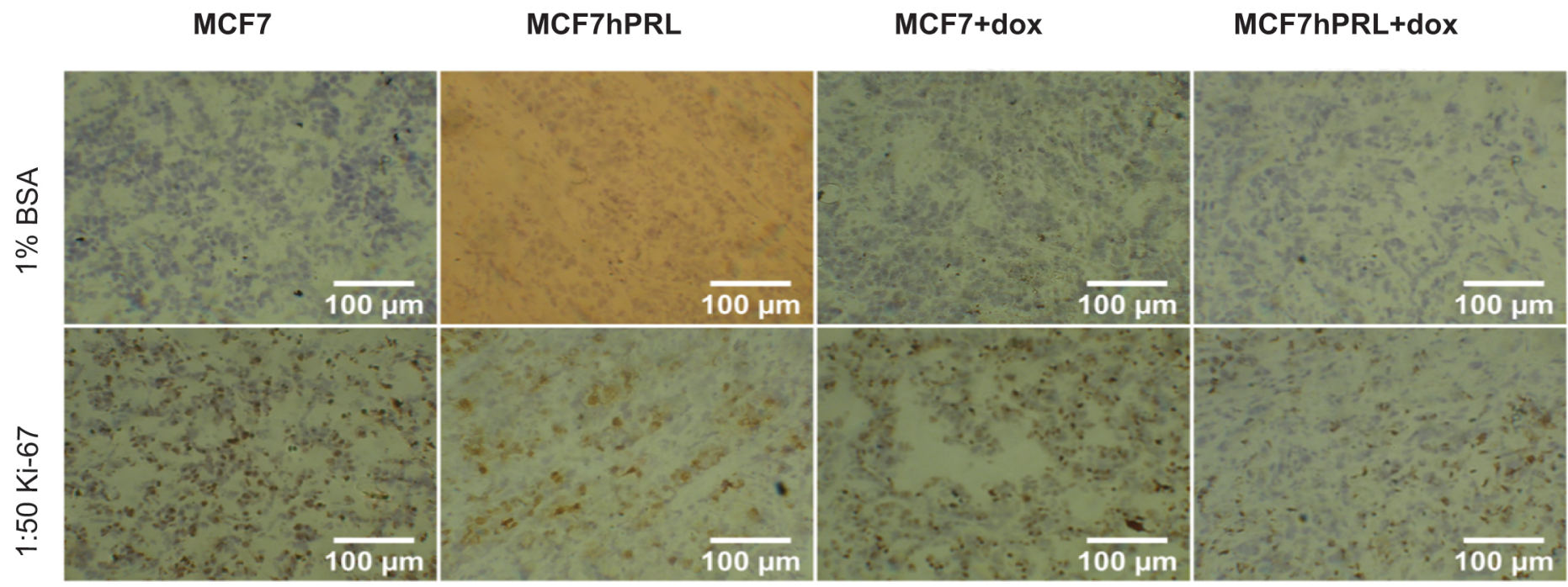

B

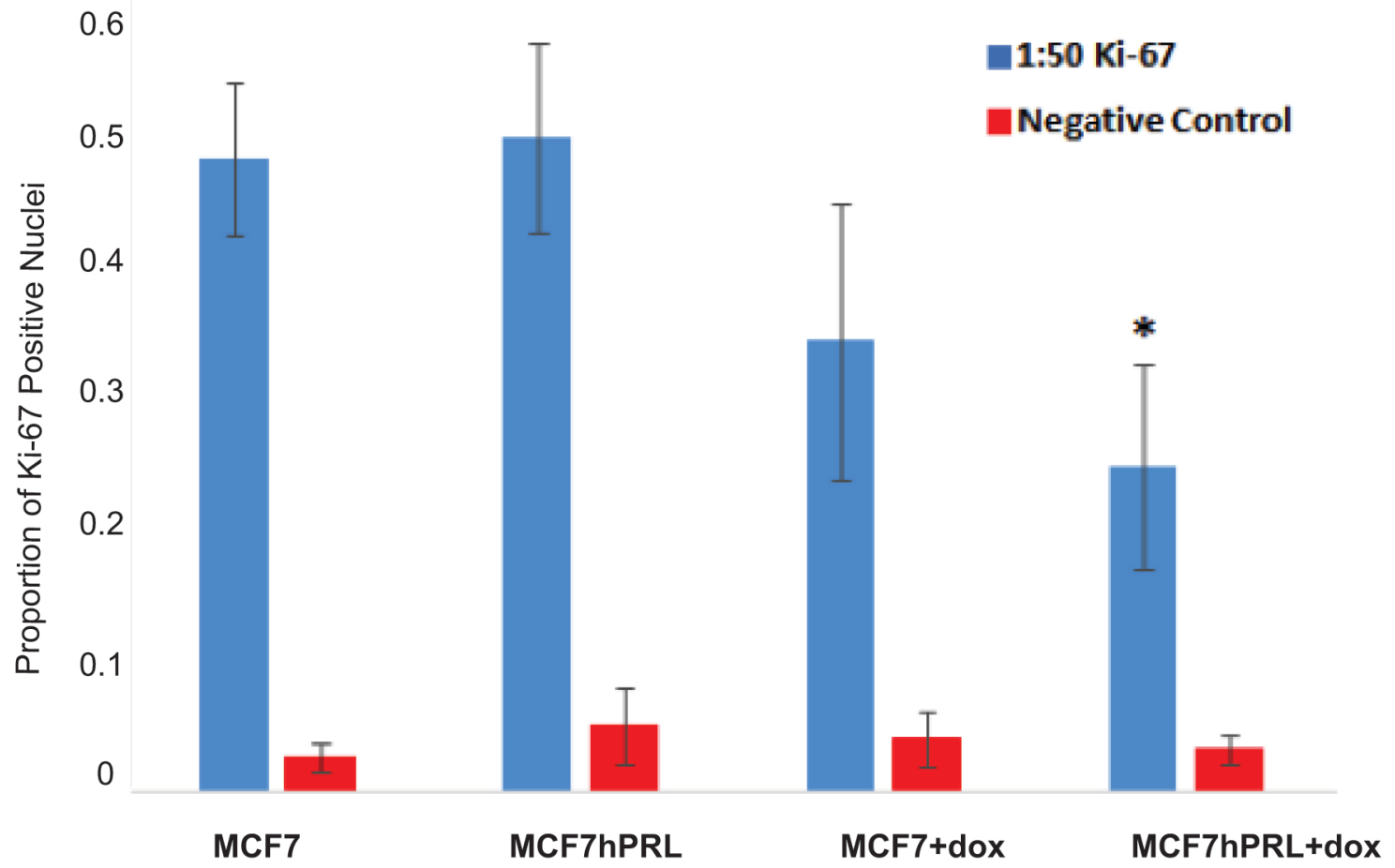


A

B
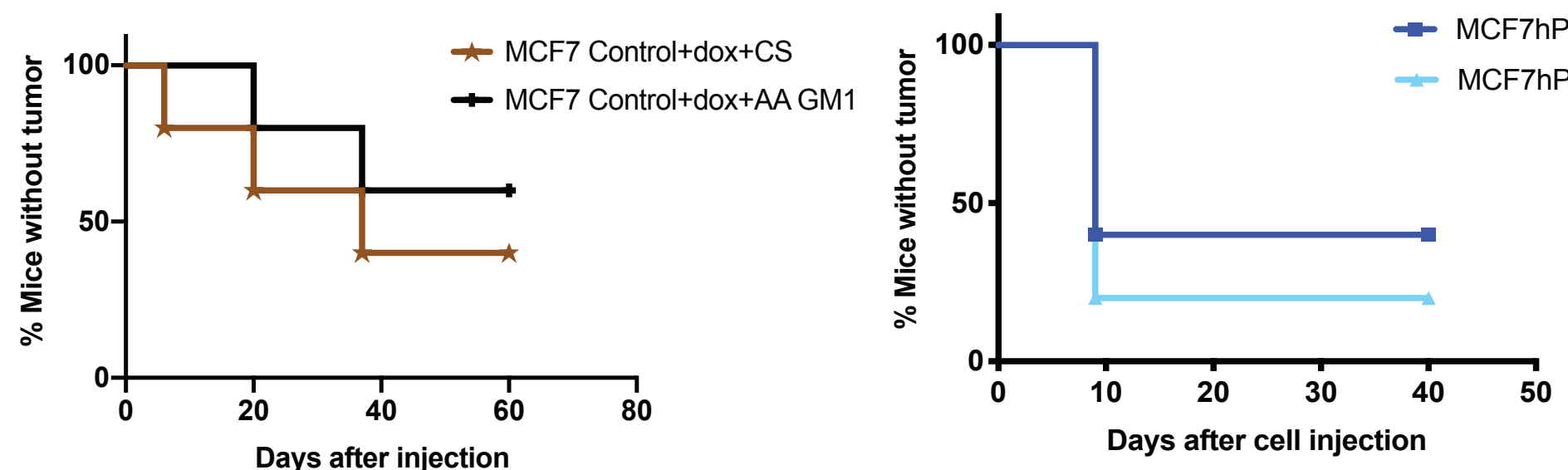

C

bioRxiv preprint doi: https://doi.org/10.1101/2020.08.31.274357; this version posted September 2, 2020. The copyright holder for this preprint (which was not certified by peer review) is the author/funder. All rights reserved. No reuse allowed without permission.

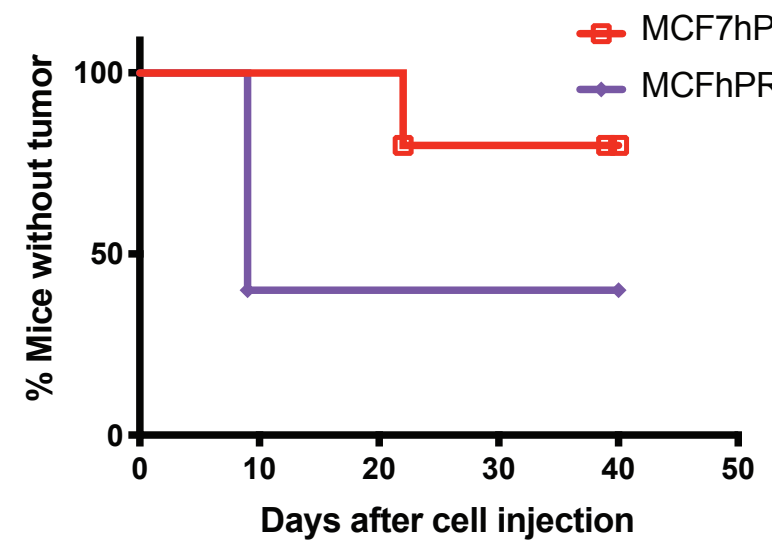

$\mathrm{D}$

E
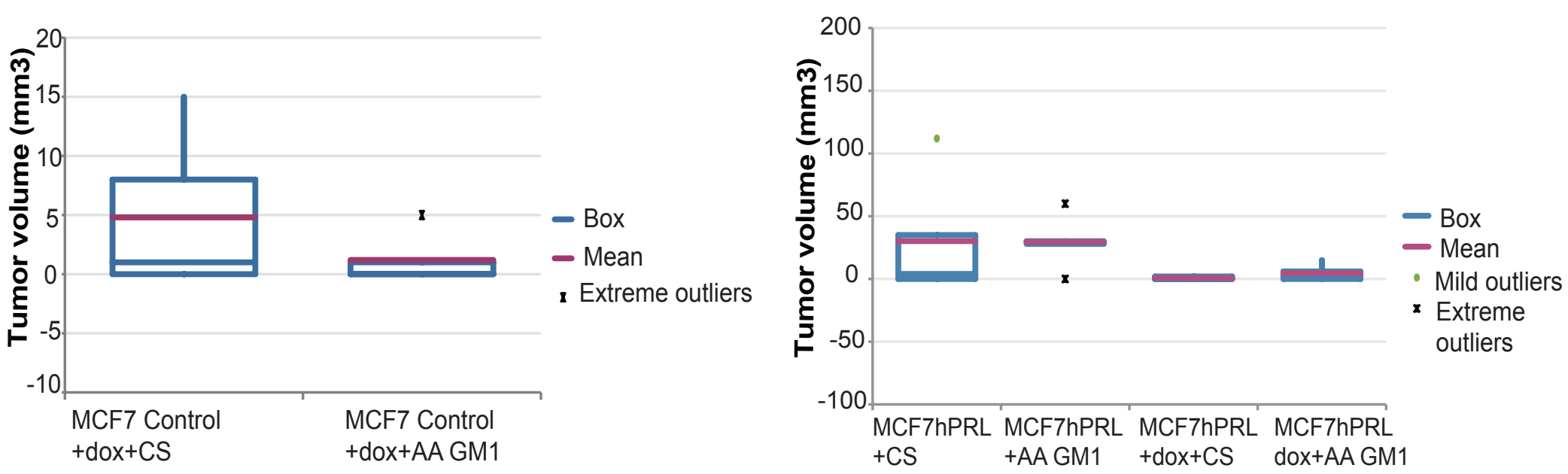